\title{
RECLAIMING THE SPACE FOR STORYTELLING IN UGANDAN PRIMARY SCHOOLS
}

\author{
Medadi E Ssentanda \\ Makerere University \& Stellenbosch University \\ Sam Andema \\ Aga Khan University (AKU)
}

\begin{abstract}
The purpose of this article is to highlight teachers' beliefs and practices towards storytelling in the mother tongue in Ugandan rural classrooms and the effect this could have on efforts to promote reading, such as the mother-tongue (MT) education programme in Uganda and the African Storybook Project (ASb). The article demonstrates that although there are initiatives to promote storytelling in the mother tongue in Ugandan primary schools to enhance reading and literacy acquisition, teachers are not prepared for the task and, therefore, disregard storytelling in the mother tongue. This disregard of storytelling in the mother tongue stems from the fact that teachers view storytelling as a waste of time, time that can rather be spent on 'real' lesson content. Furthermore, they feel that storytelling adds unnecessary pressure to their already demanding workload. Moreover, learners are not assessed for storytelling at the end of their primary education. In addition, teachers are not trained on how to integrate storytelling in their teaching practices. The article presents classroom-based research which highlights teachers' practices towards storytelling. The article ends with a request for ethnographic fieldwork to educate teachers on the social-cultural values of storytelling beyond learner assessments (among other benefits) and to facilitate teachers on how to integrate stories in the learning process.
\end{abstract}

Key words: Storytelling, literacy, mother tongue education, teacher attitudes and practices, African storybook project, Uganda

\section{BACKGROUND TO THE STUDY}

Before colonisation, Uganda, like many other African countries, had a very rich tradition of storytelling - an effective means of sharing and transferring cultural knowledge and assisting with the moral upbringing of young people. The richness of African oral tradition in general and of storytelling in the vernacular has been well documented (Bukenya, Gachanja, \& Nandwa, 1996; Mushengyezi, 2003; p'Bitek., 1986; Ssekamwa, 2000; Tiberondwa, 1998). Before the development of reading and writing in Africa, the African people mainly used storytelling as a method of preserving their historical and cultural values (Chavunduka, 1997; Vambe, 2001). In pre-colonial Africa people did not go to school, but they were well educated through the oral tradition of storytelling through which they did not only learn to amuse and entertain themselves, but also to 'develop speaking and listening skills and to learn the beliefs, values, and acceptable social behaviour of their communities' (Bukenya, Gachanja, \& Nandwa, 1996:9). According to Bukenya, Gachanja and Nandwa (1996), oral 
literature such as storytelling, played an important and variable role in the everyday existence of the African people. To this end, storytelling was a source of entertainment for soothing the mind and refreshing the brain. It made people become more aware of themselves, their fellow human beings, their environment, and their history. It added to their imagination and made them more creative. It also played a key role in socialising people - making them more productive and responsible members of society - and instilling in them the beliefs, the morals, the concerns and the aspirations of the society. Most importantly, storytelling developed people's skills for listening and speaking for effective communication.

The important role that oral literature has played in African societies is further highlighted by Mushengyezi (2003) who argues that indigenous media forms such as storytelling have continued to present themselves as effective channels of communication in predominantly rural societies where the population is predominantly orate rather than literate. He advises policy makers not to overlook the significant role that indigenous forms of communication play in the lives of ordinary people. Mushi (2009) asserts that traditional African education was an integral part of the African people, which was stored in various forms and transmitted through various modes including language, music, dance, proverbs, myths, and stories. According to Mushi (2009: 34), traditional African education that was mainly passed by word of mouth from one generation to another, had to a large extent become 'the basis for sustainable development for many centuries-, stressing that this mode of education had by and large become 'the basis of lifelong learning' among the African people.

However, when the European Christian missionaries introduced formal education in Uganda in the 1890 s, they made very little or no effort to integrate the rich oral tradition of the African people into the formal system of education. Instead, formal education disregarded the African oral traditions and emphasised the teaching of reading, writing, and arithmetic in schools with the goal of creating a literate society. The foundation that the Christian missionaries laid for the exclusion of African cultural practices such as storytelling from the curriculum has remained a feature of the Ugandan education system under the colonial and post-colonial governments. Several political leaders and scholars (Nsibambi, 2000; Sanyu, 2000) have expressed concerns over the promotion of what Parry (2000: 62) refers to as 'schooled literacy' which essentially controls access to the metropolitan social structure and hence modern international culture. Nsibambi and Sanyu have argued that schooled literacy plays a significant role in class formation and in directing away successful individuals from the rural communities. They further posit that because of the importance that schooled literacy attaches to summative examinations, it tends to encourage only a limited form of reading, one in which the reader struggles alone with text and tries to learn and understand every word, but does not apply the information in any practical way.

In 2007, a new curriculum commonly referred to as the 'Thematic Curriculum' was launched in Uganda to address some of the concerns that had been raised about the education system, including its inability to integrate local knowledge and community practices into the national curriculum. The 'Thematic Curriculum' is based on three main principles: (1) the need to focus on literacy, numeracy, and life skills development at lower primary level; (2) the holistic treatment of concepts that are meaningful and relevant to the learner; and (3) the presentation of learning experiences through multiple modes such as play, games, drawing, singing, and stories (NCDC, 2008: iv). The curriculum specifically requires teachers to use the local language to teach literacy from Grade (Primary in the case of Uganda) 1 to 3 with Grade 4 as a transition class in which teachers are encouraged to gradually shift from the use 
of the local language to the use of English as a medium of instruction. From Grade 5 onwards, teachers are required to use English as the medium of instruction and mother tongue to be taught as an examination subject. However, the major challenge with the implementation of the thematic curriculum has been the lack of instructional materials, particularly reading materials, in local languages (Ssentanda, Huddlestone \& Southwood, 2016; Stranger-Johannessen \& Norton, 2017). To address this challenge, the Government of Uganda has encouraged Non-Governmental Organisations (NGOs) and Civil Society Organisations (CSOs) to come up with interventions that complement efforts to improve the quality of Ugandan education.

In 2013, in response to Government's call for partnership with NGOs and CSOs to improve Ugandan education, Uganda was selected as one of the pilot countries for the implementation of the African Storybook project (ASb). The ASb is a digital initiative of the South African Institute for Distance Education (SAID) that promotes multilingual literacy for African children by providing openly licenced children's stories in multiple African languages, as well as in English, French and Portuguese (Stranger-Johannessen \& Norton, 2017). The ASb has been viewed as a powerful interactive website with more than 650 unique stories and more than 2500 translations produced for the pilot sites of Uganda, Kenya, South Africa and Lesotho, as well as a dozen other countries, and which are freely available for access, download, translation and adaptation. There are a total of 14 pilot sites, and most of the selected schools are primary schools. Several other similar initiatives that seek to promote the use of local cultural linguistic resources, such as stories, have been introduced to foster literacy development and improve learning achievement in Ugandan primary schools.

While studies have been conducted on some aspects of the implementation of the 'Thematic Curriculum' very little, if any, studies have been conducted on the attitudes of the teachers to implement this curriculum towards the use of stories as pedagogical tools to improve literacy in Ugandan primary schools. Miller and Pennycuff (2008) contend that if storytelling as a pedagogical strategy is to be effectively employed, teachers' attitudes and experiences with the use of stories need to be interrogated. The purpose of the present study was, therefore, to examine teachers' attitudes towards the use of local stories in the teaching of literacy in selected Ugandan primary schools. The study also explored how teachers' attitudes towards the use of local stories in the mother tongue in the teaching of literacy have impacted their professional practice. The study argues that storytelling in the mother tongue could develop learners' L1 more strongly and that the benefits of a well-developed L1 would provide a strong basis for learning the L2 (English) with ease (Heugh, 2011; Butzkamm, 2003). In the next section, we discuss the curriculum guidelines provided by the National Curriculum Development Centre for storytelling in P1 to P3.

\section{Curriculum guidelines for storytelling in Ugandan primary schools}

The National Curriculum Development Centre (NCDC) (2008, 2007a) stipulates strategies on how teachers should plan and practically engage learners to attain listening, speaking, reading and writing skills. The NCDC (2007b) argues that for learners to be fully competent and literate in language use, they must have a strong oral command of the language. The NCDC (2006a: 5) points out that storytelling is intended to develop learners' skills, namely, 'listening, speaking, imagination, creativity and appreciation'. These skills are set out to be achieved during the classroom period dubbed 'Literacy hour' in Primary education (P1 - P3). In addition, the NCDC (2007b: 31 ) contends that 'a typical literacy hour in P1, for example, will consist of “... reading a short story from the Teacher's Resource Book or from the 
teacher's own collection of stories." 'In sum, the NCDC names storytelling as one of the procedures for literacy attainment in lower primary.

The NCDC provides six Teaching Procedures for literacy development. For purposes of this article, we will refer to one (the third) procedure, namely, Teaching Procedure 3: Developing oral skills (NCDC, 2007a: 31-38). This strategy is aimed at the development of learners' oral activities. The NCDC suggests that this can be achieved through songs, rhymes, games and listening to and telling stories. A teacher is advised to use his/her own experience to tell stories or at times to use the stories contained in the Teachers' Resource Book.

Teachers are at all times encouraged to provide learners with the background and essence of the song/rhyme or story. A teacher can also use pictures to tell stories to the learners. This should be done by engaging learners through asking them questions, to repeat after the teacher or to read by themselves. These activities should be based on the abilities of the learners. In the same way, teachers are encouraged to invite a local storyteller to school. The NCDC prescribes that this is done to provide for extended development of the local linguistic heritage and development of learners' linguistic repertoires in other linguistic elements, such as similes, proverbs and culture. Through storytelling, learners can also begin to appreciate the extended time of listening and the literacy elements embedded in stories such as plot, dialogue, etc. These skills are key to language learning. When such skills are developed in learners' mother tongues, they can be transferred to other languages as well. In this way, the foundation of biliteracy, namely encouraging the mother tongue, is achieved.

\section{THEORETICAL AND CONCEPTUAL BACKGROUND}

This article is guided by the social constructivist theory (Palincsar, 1998) to illuminate the relationship of storytelling and literacy development as well as the possible benefits of storytelling to literacy acquisition for young learners. This theory considers schooling as an enculturation process. Enculturation refers to the process of acquiring the norms, values, practices and characteristics of a given culture. In other words, children learn and acquire their cultural norms and values through stories as these touch on various aspects of a given culture. However, this would only be possible if the school curricula were not removed from the context in which the school is situated (cf. Bloch, 1999, 2000). As a point of departure, we draw from Palincsar's (1998) review of the Social constructivist perspectives on teaching and learning to show the reciprocal benefit between storytelling and language learning. Palincsar's (1998: 354) study reveals that 'learning and development take place in socially and culturally shaped contexts (...). A school is a learning community and a community of practice for that matter from which children are introduced to, acquire and practice the learnt skills.' Nevertheless, studies show that school can distort what children already know (Cummins, 1991). One of the reasons given for this failure is the discontinuity that exists 'between the culture (values, attitudes, and beliefs) of the home and school' (Palincsar, 1998: 368). As Cummins (1991) has demonstrated, children join school with language as a resource. The children possess knowledge and language skills (for example telling simple stories), a resource that should be exploited and enhanced by the school in order to foster learning.

Furthermore, storytelling lends itself to the constructivism approach to learning. Constructivism enables learners to actively participate in the learning process rather than the teacher alone. As storytelling calls for active participation, there is much for learners to 
experience and learn in the process as pointed out earlier. Furthermore, authors of stories have observed that through storytelling, learners' oral language development is enhanced and their vocabulary is enriched (Ekibiina ky'Olulimi Oluganda, 1960; Segganyi, Kizito, \& Mukalazi, 1958).

In this article, we also invoke the multilingual and biliteracy concepts to reflect on the teachers' attitudes and practices and how these can potentially undermine the efforts of promoting storytelling in the mother tongue and ultimately negatively affect literacy acquisition of the learners in the practice of mother-tongue education (Ball, 2011; Benson, 2008; Hornberger, 2002). As mentioned earlier, research has revealed that children join school with a social-cultural capital which teachers should exploit and enhance to foster multiple literacies. Literature in multilingual education indicates that a firm foundation in the mother tongue enhances the acquisition of the L2 (Heugh, Benson, Bogale, \& Yohannes, 2007; Manyak, 2006; Hornberger \& Skilton-Sylvester, 2000). In addition, a strong foundation in the L1 is a basis for the development of literacy in the two languages, i.e. mother tongue and English. As storytelling builds learners' language skills in terms of inter alia vocabulary, conversation skills and cultural values, the development of biliteracy is ensured. Therefore, this article aims at exploring the teachers' reasons for disregarding storytelling in the teaching and learning process and how such attitudes and practices can possibly challenge the noble initiatives of storytelling in enhancing literacy acquisition in Ugandan primary schools.

\section{Storytelling and literacy development}

In the African context, storytelling plays a very important role in the lives of its people (Mushengyezi, 2003). Stories reflect the culture (values, beliefs, customs, etc.) of the people and is one of the ways through which norms, values and codes of behaviour of a community is handed down from one generation to another. Even though storytelling has been present in many African contexts from time immemorial and notwithstanding the provision for storytelling in the language-in-education guidelines, very few stories find their way into the teaching and learning environment in African classrooms today. This can, amongst other things, be attributed to misconceptions that exist around mother-tongue (MT) teaching and the disjointed teacher training versus actual practice(s) (Abiria, Early \& Kendrick, 2013; Ssentanda, 2013). Some of the misconceptions, for example, include the belief that the earlier one begins to learn English (or whatever the language of instruction is in a given situation), the sooner the language will be acquired, and the best way to learn a second language is to use it as a language of learning and teaching. (Benson, 2008; Dutcher, 2004; McLaughlin, 1992). In the school system, storytelling has also been affected because of the break in the social organisation of this practice. Ngwaru (2011) observes that in most African classrooms, teachers neglect learners' MT and their socio-cultural practices of which storytelling is a part. Moreover, even though some families still practice storytelling, the practice is also affected in some way because of the introduction of Western education and technological development (e.g. radio, television, internet and social media platforms, such as WhatsApp, Facebook, Twitter, etc.), and thus storytelling is slowly disappearing from many families. Moreover, parents' beliefs about the 'importance' of English also undermines the practice of storytelling as many believe that storytelling in children's MTs might undermine the acquisition of this language. 
In her article, Why stories matter for children's learning, Albers (2016: 3) notes that 'stories have a strong influence on children's understanding of cultural and gender roles. Stories do not just develop children's literacy; they convey values, beliefs, attitudes and social norms which in turn, shape children's perceptions of reality.' She emphasises that stories can accomplish these roles whether they are orally told, read or passed on through songs. Albers (2016) further states that children begin to form their attitudes and appreciate cultural issues even before they begin to learn to read. They identify themselves with characters in the stories and eventually this influences their identities, wa Thiongo (1986) makes a similar point to that of Albers (2016) when he states that at the time he was a child, children identified themselves with the characters in the stories which they heard and engaged in telling as well and that this greatly influenced their lives and view of the world. What is more, storytelling encourages children to begin to learn to read. Stories are interesting and children enjoy them. Storytelling, therefore, promotes reading as children search for a told story in text form (Bustamante, 2002). Peck (1989: 139) points out that 'many tellers attest that young children will often ask to read a particular book after hearing it told.' In sum, storytelling encourages children to begin to read.

Furthermore, Bustamante (2002) points out that storytelling is As an activity involves both social and cultural experiences and that children find it a storytelling a link between oracy and literacy. Moreover, 'children need to be afforded the chance to start from their own familiar home setting with curriculum and pedagogy that recognise their cultural heritage' (Ngwaru, 2011: 237). From a social constructivist point of view, children (Palincsar, 1998) gain interest in reading when they hear and see stories read to them by either teachers or parents. This is reason enough to incorporate stories into the teaching and learning process. Bustamante, (2002) and Peck (1989) advise teachers to encourage learners to write/compose their own stories as before long they will love reading and writing as they copy from the familiar stories. Similarly, storytelling has also been shown to promote reading comprehension and writing (Miller \& Pennycuff, 2008; Craig, Hull, Haggart \& Crowder, 2001) and enhances expressive and receptive language development (Peck, 1989; Cliatt \& Shaw, 1988). This is possible because stories have a structure like that of written text, i.e. an introduction, a body and a conclusion. Besides, Miller and Pennycuff (2008) observed that storytelling can remove the fear of written forms from learners. Therefore, storytelling is an invaluable activity, particularly in the early years of learning.

In view of the fact that teaching and learning in many African classrooms is dominated by teachers, (Heugh, 2013; Chimbutane, 2011; Bunyi, 2001; Chick, 1996) it is apt to examine how teachers' beliefs and practices can affect the use of stories in the learning process.

\section{METHODOLOGY}

The findings reported here were part of a larger ethnographic $\mathrm{PhD}$ project which focussed on teachers' understanding and management of the process of transitioning from MT as LoLT to English medium in Ugandan primary schools. This is a qualitative survey study within which data were collected using questionnaires, semi-structured interviews, and classroom observations. Using these instruments, we aimed to capture teachers' and learners' demographic data (including languages they speak); teachers' opinions on the language-ineducation policy and the thematic curriculum; teachers' classroom linguistic practices; the preparation for, and assistance offered to learners in the process of the transition from the MT to English as language of teaching and learning; and teachers' views on how to improve the 
teaching of the MT and the implementation of the thematic curriculum. Further details of the methodology can be seen in Ssentanda, Southwood and Huddlestone (2019). Data were collected over a period of two months. The findings reported here were collected in primary one (P1) to P3 classrooms. Learners in these classes are between 6 and 9 years old. Data for this study were collected from four rural schools, two government and two private.

\section{ETHICAL CLEARANCE}

Ethical clearance for this study was obtained from the Research Ethics Committee (Humanities) of Stellenbosch University, South Africa and the Uganda National Council for Science and Technology (UNCST) before data collection was done in 2012.

In the section that follows, we present the study findings in answer to the questions that guided this article, i.e.

(i) What effect could teachers' beliefs and practices have on the reading and literacy improvement initiatives such as the ASb?

(ii) What can be done to reclaim the practice of storytelling in Ugandan classrooms?

\section{FINDINGS}

The findings presented here relate only to the classroom observation and teacher interview data collected from rural primary school teachers. The data discussed here were collected from rural primary school teachers because the language-in-education policy requires rural schools to teach the MT programme under which storytelling falls. The first question will be answered in the first section below and the second will be answered in the section that follows. The subheadings within the first section relate to the two challenges which support the disregard for storytelling in Ugandan schools. The first is that storytelling (the MT) is not examined at the end of primary schooling, and secondly, teachers are not trained on how to integrate storytelling in the teaching and learning process.

\section{Examination content}

Bloch (2000: 26) states that 'there is recognition of the importance of stories, but little time for them in many early childhood classrooms' Bloch (2000:28) further emphasises that 'hearing stories is the most crucial factor to later educational success'. Similar to what Bloch (2000) observes, teachers interviewed in this study expressly indicated that they do not see a need for teaching storytelling (cf. Ssentanda, 2013) because of one major reason. The MT is not assessed at the end of the learners' primary education. Storytelling would feature in an MT examination. Consequently, teachers categorised subjects into 'major' and 'minor' subjects. According to the teachers, subjects, such as mathematics, that are assessed, are the 'majors'. The so-called 'minors' are those subjects not assessed, for example MT under which storytelling falls.

In this study we sought to ask teachers to prepare a lesson in one of the 'minor' or nonassessed learning areas to observe how it is handled. In Extract 1, the authors engaged a teacher in an interview to seek her permission to observe her teach a news lesson/period, in order to determine what takes place in such a lesson. In the interview (Extract 1), the teacher reveals that they did not only disregard the news period, but oral literature/storytelling was also not regularly taught as prescribed by the curriculum. The teacher discloses that 
storytelling and news reporting were neglected because these subjects are not assessed; instead teachers concentrate on what they are sure will be assessed.

Extract 1, and the extracts that follow, form part of interviews and classroom observations from two rural sets of schools. School B is a government-owned school while school C is a privately-owned school in the Rakai district. These extracts illustrate that rural primary school teachers seem to pay little attention to storytelling. The interview was conducted in Luganda (see bold text) and an English translation is given in bold italic font. For ethical reasons, the teachers' turns are marked with T, the researcher's turns with RS and learner(s)' turns with L(s). Learner participation was cued or prompted by a teacher's rising tone of voice and this is marked by $\left(^{\wedge}\right)$ in all extracts.

\section{Extract (1): Interview extract with a P3 teacher in school B (government school)}

${ }_{1} \mathrm{~T}$ : Ahaa, ebintu bingi, era nze ebiseera ebisinga, ntera okusomesa writing, n'ey'okusoma n'okuwandiika bye nsinga okuteekako amaanyi. Olumu ne tugendako ne mu P.E kale. Naye ebyo mbu olulimi olwogere, oyo literature, kale tutera kusomeramu ngero. Nazo ezo mu butuufu nnyinza okukugamba nti mu wiiki nnyinza okukikolamu omulundi gumu kubanga, ebyo bitera okujja mu paper, abaana bababuuza engero ensonge ezo. Kati ne ndaba engero eziri mu theme eyo gye tuba tukoze ki? Ze tuba tusomyeko. Ne nzibasomesa. Ne mbigattikana byonna oba bibadde mu periods ssatu, ne mbigatta wamu ne mmanya nti kasita bano bakoze ki? Babifunye.

Yes, the load is too much. For me most of the time I teach reading and writing, that is where I put most of the effort. At times we go into P.E [Physical Education]. But such things like oral literature, literature; we sometimes learn it through proverbs. But even for that, I could say that I do that once a week because such usually comes in exams; learners are sometimes asked about those proverbs. So I look up proverbs related to the theme that we would have looked at; then I give them to learners. I combine them like that, whether it is content for three lessons, I just combine them all at once and then I know that all has been.

${ }_{2} \mathrm{RS}$ : Uhm.

Yes.

${ }_{3} \mathrm{~T}$ : Naye nga news tetutera, ekyo sijja kukulimba.

But for the news, we do not usually do it, I will not lie to you.

In Extract 1, the teacher reveals that she only concentrates on reading and writing, but that in the case of oral literature, the period for storytelling (see underlined text), she only picks out proverbs that she thinks would appear in an examination. Note that the teacher says that she puts emphasis on 'reading and writing'. The respondent seemed unaware of the fact that through storytelling, learners can be 'enculturated' (cf. Palincsar, 1998) and can quickly and easily develop a love for reading and later writing. Furthermore, the reading lessons (not excerpted here) this teacher mentions were mostly conducted in English (Ssentanda, 2014b). It is also deducible from this teacher's narrative that if a subject is not assessed it is not given attention in class. The reading that learners engaged in during the observed class were sentences that the teacher wrote on the blackboard, and both the teacher and learners engaged in an exchange of reading those sentences. For the greater part of the lesson, learners repeated after their teacher and it appeared that the teacher's aim was not to teach learners to read independently what was written on the chalkboard, but to merely repeat what the teacher had read out. Thus, it seems that examination content seems to be the driving force for the teaching and learning in these schools. 
We should also point out that the timetables that teachers had in their staffrooms allocated time for say MT (as subject) and news (as a period). However, when such time came, teachers converted those periods into other learning areas, for example, social studies and English. For instance, respondents pointed out that if a learner was struggling in mathematics, they found it had more value to continue teaching mathematics rather than teaching MT (cf. Ssentanda, 2013). The teachers' attitude and practices towards the teaching of MT and/or storytelling reflects the weaknesses in the language policy which provides for the teaching of MT but without assessing the learners at the end of their primary education. This study's finding is similar to that of other scholars who have studied tests and examinations in languages to be a signal of whether a language is important in education or not (Makoni, 2011; Shohamy, 2006). It is, therefore, logical and natural for teachers to disregard a subject which, at the end of schooling, is not to be assessed.

Bloch (2000) explains that although teachers recognise that stories would help learners, they regard them as extra work because they are under pressure to catch up with the syllabus. In the larger study, teachers said that the thematic curriculum was over-loaded (Ssentanda 2013). Recall Cummins's (1991) observation that schools distort what children already know and they do not build on this knowledge. As stories are told in learners' MTs, they would provide a link between the home and the school. Unfortunately, teachers are only interested in teaching subjects that will be assessed, as discussed in the next section.

\section{Lessons are structured in form of examination questions}

Furthermore, as examinations are the motivation to teaching, teachers tends to structure their lessons in the form of examination questions. We use an example of a Religious Education class in private school $\mathrm{C}$ to illustrate this (see extract 2 below). In this class, the teacher introduces the lesson with a question. In turn 8 , the teacher asks learners to read what he had written on the chalkboard. In line 12 , the teacher immediately introduces a question and mentions to learners that such a question could feature in an examination (turn 13). It is doubtful whether there was meaningful learning in this class as the teacher and learners only appear to engage in questions and possible answers to them. Interestingly, the topic that this teacher 'taught' involved a Bible story, namely the story of the Israelites in Egypt - which the teacher should have narrated to the learners or he could have asked the learners whether they had heard of that story. This would have helped the teacher to know the extent of learners' knowledge about this story. Nevertheless, this did not happen and could possibly be attributed to the fact that the teacher was aware that the 'the bigger story' of the Israelites in Egypt was immaterial in an examination-oriented form of teaching. He, therefore, preferred to focus only on questions around 'this story' without telling the story itself. One is left to imagine how the situation would have been if the teacher had shared the story of how the Israelites came to live in Egypt and how and why they left. Learners would probably have found this story interesting and would have been able to easily recall the events in the story, instead of only looking at it in the form of questions and answers. Similar to Chick's (1996) observations, the teacher in this class practiced 'safe-talk' and only encouraged preparation (to $\mathrm{cram}$ ) for passing examinations.

Extract (2): Classroom observation with a P3 teacher in school C (private school)

${ }_{1}$ Ls: $\quad$ Clap hands to welcome teacher. You are most welcome dear teacher.

${ }_{2} \mathrm{~T}$ : Thank you, Good morning!

${ }_{3}$ Ls: $\quad$ Good morning teacher. 


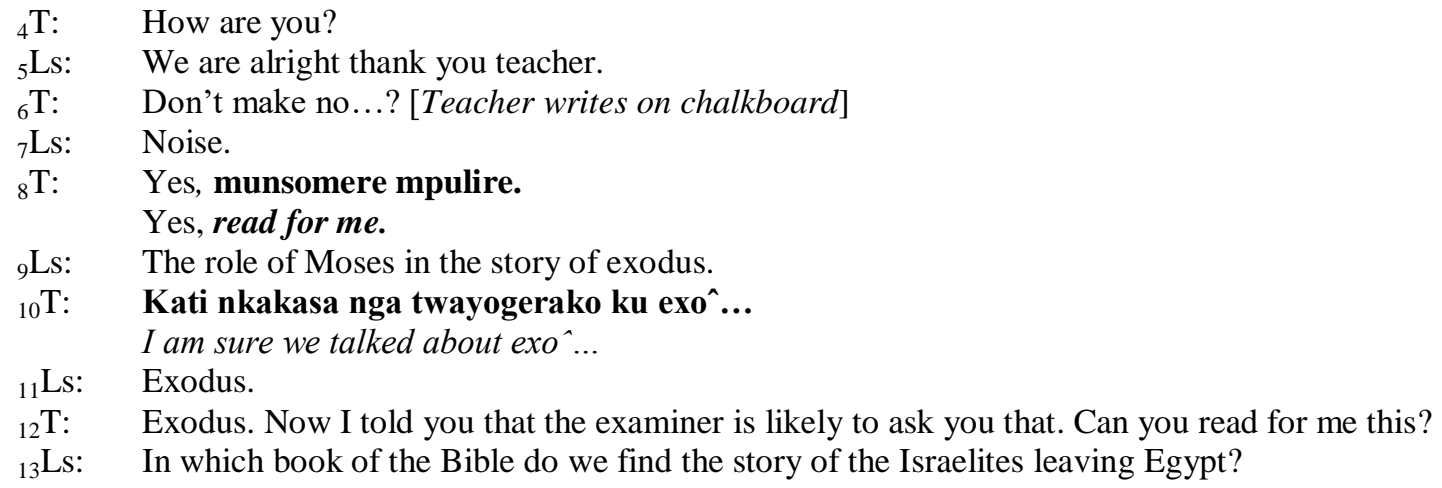

As the lesson progresses, the teacher emphasises the issue of examinations to the learners. In this extract, the teacher switches to Luganda to emphasise what he wants to say, namely, that if such a question appeared in an examination, the learners were required to cram the answer (see turn 14).

${ }_{14} \mathrm{~T}$ : So singa nnaakubuuza ekibuuzo kino njagala okicraminge oba okikwate. In which book in the bible do we find the story of exo^..

So if I ask you this question, I want you to cram it. In which book of the bible do we find the story of exo ${ }^{\wedge}$...

${ }_{15}$ Ls: $\quad$ Exodus.

${ }_{16} \mathrm{~T}$ : $\quad$ Sorry, in which book of the Bible do we find the story of the Israelites leaving Egy...

${ }_{17}$ Ls: $\quad$ Egypt.

${ }_{18} \mathrm{~T}$ : The answer is Exo^...

${ }_{19}$ Ls: Exodus.

${ }_{20} \mathrm{~T}$ : Exodus means?

${ }_{21}$ Ls: Going out.

${ }_{22} \mathrm{~T}$ : The word exodus means?

${ }_{23} \mathrm{Ls}$ : Going out.

${ }_{24} \mathrm{~T}$ : $\mathrm{O}^{\wedge} \ldots$

${ }_{25} \mathrm{Ls}: \quad$ Out.

In turn 16, the teacher gave the learners the question and an answer followed in turns 18 and 19. This means that learning in this class was driven by the examination questions that are likely to appear in the examination, rather than learning and/or understanding of concepts. This form of classroom discourse is typical of 'safe-talk, chorusing, memorisation and parroting' as described by Brock-Utne (2004) and Hornberger and Chick (2001).

Most teachers have stories, but the National Curriculum Development Centre (2006) has also provided sample stories in teachers' resource books. However, the challenge is that teachers in this study consider storytelling a 'waste of time' because of the over-emphasis of examinations and little time is spent on making sure learners understand what is taught in class. This form of approach to teaching and learning to a large extent undermines the approaches to the acquisition of literacy and instil the spirit of yearning for reading among learners (cf. Kyeyune, 2003).

\section{Pre-service teacher training and use of MT}

In addition to the fact that teachers seem to focus on teaching what they expect will appear in examinations, in Primary Teacher Training Colleges, no local languages are taught to prepare teachers for subsequent teaching of local languages in schools. See Extract 3 from a follow- 
up interview with a P1 teacher in school $\mathrm{B}$, in which it is stated that there was no training related to MT teaching in her Primary Teacher Training College.

Extract 3: Teachers receive no MT training in PTCs

T: Mu college? Mu college, subject nnya zokka ze bahandlinga era ze basuubira, science, kubala, cultural kale mwe muli RE kati n'Oluzungu. Kati eno eby'okudda mu local language tekiriiyo. Kati bye batutrainingamu by'ebyo kati eno tujja tumusanga nti tulina kusomesa ate mu local language.

In the college? In the college, they only handle four subjects which they expect [to be taught in primary schools]: science, mathematics, cultural studies. In cultural studies we also find $R E$ [Religious Education] and English. Local language is not taught there. It is in these areas that we received training but on coming out we are told that we have to teach through local language.

Teachers who have not had the chance to opt for a local language as a subject at secondary school level, therefore, find teaching a local language or using such language as LoLT challenging, because they have had no training on the local language since primary school. Heugh et al (2007: 6-7) have observed that '[t]he MOI [medium of instruction - MS] for teacher training should match the MOI teachers will be using because teachers themselves need to develop their mother-tongue skills, as well as the technical and pedagogical vocabulary and language structures needed to convey concepts in their subject areas'. Teacher preparation and training in Uganda falls short of the two criteria that these authors set: The majority of Ugandan teachers do not have formal training in their MTs and do not possess 'the technical and pedagogical vocabulary and languages structures' needed to instruct the curriculum content and the MTs themselves. Therefore, it is against this background that teachers see no value and a place for storytelling in the classroom environment.

From a social constructivist view, teachers' insights and practices did not support the employment of stories in the learning process. The findings suggest three reasons for this challenge: (a) teachers regarded storytelling as extra load; (b) they were not prepared (at College) on how to use stories in the learning process even though there is no shortage of stories, and (c) the fact that MTs are not examined at the end of primary education.

\section{Alternative sources for stories and the availability of MT stories in Uganda}

In this section, we attempt to provide an answer to our second research question, namely, what can be done to reclaim the practice of storytelling in Ugandan classrooms? In today's global and multilingual world, much is shared, heard and seen in the communities in which children live and attend school. Children have many stories to tell and share with their peers if given the opportunity in a classroom environment. Through stories, children would naturally learn about many things. However, it requires the creativity of teachers to make storytelling part of the learning space. Still, as mentioned earlier, as teachers find it difficult to practice what they did not learn at college, it is a big challenge to practice what they themselves have not experienced. Accordingly, the Ministry of Education and Sports in Uganda, in conjunction with other organisations working on this initiative of storytelling (e.g. ASb, RTI, etc.), needs to train and guide teachers on how to integrate aspects of storytelling in the MT in lesson planning in a way that would enhance learning. 
Storytelling as an activity has greatly changed in recent times and is presented in various forms. It is recommended that teachers change their methods of teaching to match the changing times. For instance, there are online digital stories (see the ASb website), written stories, broadcast stories on television and radio. In the case of Uganda, there are initiatives of storytelling that teachers could make use of, e.g. the television programme Awo Olwatuuka, aired on Bukedde TV1. The same stories are available online on Youtube. The programme dramatises both oral and written stories in Luganda. Some of the dramatized stories are those that are written in the storybooks referred to earlier (e.g. Ekibiina ky'Olulimi Oluganda, 1960; Segganyi et al, 1958). The stories on television referred to above are broadcast in the learners' MT. In other words, teachers should see this as an opportunity and a means of bringing storytelling into the classroom.

There is research evidence to demonstrate that reading and writing concepts can be transferred through print (Martin-Jones, 2011). Moreover, as demonstrated in the previous sections, when children engage in storytelling activities in printed form, their love for reading and writing, as well as their phonological awareness for text and comprehension are enhanced (Prosper \& Nomlomo, 2016). Furthermore, Ssegganyi et al (1958: iv) in a collection of 80 stories note that stories 'aid many people in learning to converse, think aloud as well as expand their Luganda vocabulary because of the glossary of words at the back of the book' [Own translation]. Similarly, Ekibiina ky'Olulimi Oluganda (1960: v) writes that 'The aim of this collection of stories is to provide a book that would interest children in the $5^{\text {th }}$ and $6^{\text {th }}$ Grades. I hope that the children will achieve this goal and they will continue to learn Luganda and their love for the language will immensely increase'. [Own translation].

As of December 2018, the ASb has stories in the following Ugandan languages: Kiswahili (193); Leblango (7); Lubukusu (15); Luganda (289); Acholi (22); Lugbarati (91); Lugwere (18); Lumasaaba (102); Lunyole (153); Lusamia (13); Lusoga (832); Lulamogi (24); Rukiga (29); Rutooro (52). However, we are also aware that NCDC (NCDC, 2006b) has sample stories in teachers' resource books (to start with) and that there are other storybooks available in Luganda. For example, Ekibiina ky'Olulimi Oluganda (1960) 22 stories, Segganyi et al (1958) 80 stories, etc. Moreover, the Research Triangle Institute (RTI) under their initiative to promote reading and uplift literacy levels in Uganda has also embarked on developing stories in various Ugandan languages. RTI has also partnered with the ASb to avail as many stories as possible to schools in Uganda. Some of the stories will be in printed form while others are and will still be accessible online. All these efforts are intended to ease and increase access to stories in the MT.

Regarding time allocation for classroom activities, the study schools had timetables but teachers used the slots allocated to MT/storytelling for other activities and/or teaching 'major' subjects. For example, the time allocated for news telling and/or storytelling was converted into a lesson of the examination content. This means that if the status quo remains, stories in the MT may not find a place in Ugandan classrooms.

As teachers presently consider and only seem to care about teaching that which is assessed at the end of primary education, the ASb project (and the Ministry of Education) should consider training teachers on the strategies to employ stories in the learning process, as well as teach them the value of storytelling in the MT in language learning. The efforts of reviving and bringing stories into the classroom should start at Primary Teachers' Colleges (PTCs) and continue into teachers' workshops in schools. In addition, just as there have been 
initiatives to compose, translate and write stories for African languages, it would seem especially fruitful to devise means of bringing teachers together for training, orientation and demonstrating to one another on how to use stories in the MT in classroom activities. This could prove to teachers that stories cannot only make learning interesting and easier, but can also make a difference in the lives and experiences of learners and make them aware of the values embedded in their cultures.

Lastly, one of the aims of teaching storytelling and the MT is to help learners to appreciate their cultural practices and values. As mentioned earlier, televisions, radios, WhatsApp, Facebook, Twitter and other social media platforms are taking the place of storytelling in the MTs in homes. The school would, therefore, be the environment to continue and instil the practice of storytelling in the MT. However, if teachers are not prepared, guided and educated about the value of storytelling, the treasured values and practice of storytelling of African culture are in danger of extinction, given that there is now limited opportunity for continuing this practice.

\section{CONCLUSION}

In this article, we have shown instances where teachers disregard storytelling in preference for the content that will be assessed at the end of primary education. Teachers' views, attitudes and practices have to be viewed and considered within the policy (Government of Uganda, 1992) and curriculum guidelines (NCDC, 2006b, 2007a) which promote multilingualism, preservation of culture and promotion/development of bilingualism. Even if the findings of this article are based on a small sample and may, therefore, not be generalised, they could still be considered useful and informative. The findings show how teachers' attitudes and practices are an impediment to the initiatives of bringing storytelling in learners' MTs to the classroom and the benefits thereof in Ugandan classrooms. Moreover, teachers have challenges such as large class sizes, pressure to complete the curricula content - having to choose which content to teach and what to leave out (Bloch, 1999). Content considered not to be assessed, such as that related to storytelling in learners' MTs, is left out (Ssentanda et al., 2016). Also, this study has discussed the change that is needed for storytelling to be implemented more widely in Ugandan primary schools.

As demonstrated in the excerpts, teachers compel learners to 'cram' answers to questions without telling learners; the stories' behind them even when what they teach has a story that learners could easily remember. We have also discussed in this article that presently, the challenge is not that stories are not available to teachers, but that teachers need to be prepared and oriented on how to involve storytelling in the teaching and learning process (Prosper \& Nomlomo, 2016). Also, teachers need to be assisted for them to realise how storytelling and storybooks can enhance a learner who is beginning to learn to read, and to be aware that language is a resource with which learners come to class (Cummins, 1991).

\section{RECOMMENDATIONS}

In sum, the value of storytelling cannot be over-emphasised. As Pedersen (1995) points out, it is the original form of teaching even in the traditional African communities. Indeed, many rural children in Uganda share stories at home and they come to school when they already know how to relate stories, but this resource is not utilised at school because, at present, it is not part of the knowledge and skill that learners will be required to display at the end of their 
schooling or even at the end of every school term. As some of the stories learners already know by the time they enter school have now been documented by the ASb team, it would be interesting for them to learn that such stories are available and it can thus be assumed that the learners will be motivated to read these stories on their own. This can be used as an incentive to invite children to discover more stories in books. To this end, the role of teachers in encouraging this incentive cannot be over-emphasised.

As a suggestion for further research, and since the ASb has been rolled out in some parts of Uganda (as well as Kenya, South Africa and Lesotho), there is a need to work with teachers and community members to find a way to include storytelling in classroom activities. Tembe and Reed (2016) have started working on this initiative and such efforts need to be extended to other parts of the country in order to reap the benefits of storytelling in literacy acquisition and in cultural preservation.

\section{ACKNOWLEDGEMENTS}

We thank the anonymous reviewers for the useful comments that helped to shape this article. In addition, the first author (Medadi Ssentanda) wishes to acknowledge funding from the Makerere University NGAA II Carnegie fund that enabled the collection of the data. Further acknowledgement goes to the American Council of Learned Societies, under whose scholarship I managed to complete the final draft of this article.

\section{REFERENCES}

ABIRIA, D M, M EARLY \& M KENDRICK. (2013). Plurilingual pedagogical practices in a policy-constrained context: A Northern Ugandan case study. TESOL Quarterly, 47(3): 567-590. Available from https://doi.org/10.1002/tesq.119 [Accessed: date?]

ALBERS, P. (2016). Why stories matter for children's learning. Available from http://theconversation.com/why-stories-matter-for-childrens-learning-52135. [Accessed: 25 May 2017].

APPLEGATE, A \& MD APPLEGATE. (2004). "The Peter effect: Reading habits and attitudes of preservice teachers." The Reading Teacher, 57(6), 554-563.

BALL, J. (2011). Enhancing learning of children from diverse language backgrounds: mother tongue-based bilingual or multilingual education in the early years. Analytical review commissioned by the Unesco Education Sector. France: United Nations Educational, Scientific and Cultural Organization.

BENSON, C. (2008). Common themes and areas for further work: Questions, answers and remaining issues. In C. Haddad (Ed.), Improving the Quality of mother tongue-based literacy and learning: Case Studies from Asia, Africa and South America (pp. 182-183). Bangkok, Thailand: Unesco Asia and Pacific Regional Bureau for Education.

BLOCH, C. (1999). Literacy in the early years: Teaching and learning in multilingual early childhood classrooms. International Journal of Early Years Education, 7(1), 39-59.

BLOCH, C. (2000). Literacy in the early years: Teaching and learning in multilingual early childhood classrooms. PRAESA Occasional Papers No. 1.

BROCK-UTNE, B. (2004). "But English is the language of science and technology"- the language of instruction in Africa - with special look at Tanzania. CIES conference in Salt Lake City, 2004.

BUKENYA, AS, M Gachanja \& J Nandwa. (1996). Oral Literature - A Senior Course. Nairobi, Kenya: Longhorn Publishers. 
Bunyi, G. (2001). Language and Educational Inequality in Primary Classrooms in Kenya. In Voices of authority: education and linguistic difference. Westport, CT: Ablex.

BUSTAMANTE, DM. (2002). Telling our stories, finding our voices: Nurturing a community of learners. Primary Voices $K$ - 6, 11(1), 2-6.

BUTZKAMM, W. (2003). We only learn language once. The role of the mother tongue in FL classrooms: death of a dogma. Language Learning Journal, 28, 29-39.

CHAVUNDUKA, GL. (1997). Traditional medicine in modern Zimbabwe. Harare: University of Zimbabwe Publ.

CHICK, JK. (1996). Safe-talk: Collusion in apartheid education. In H. Coleman (Ed.), Society and the Classroom (pp. 21-39). Cambridge: Cambridge University Press. Available from http://ematusov.soe.udel.edu/CH-SIG/Document Library/Chick, Safetalk in SA apartheid classroon, 1996.pdf [Accessed: July 15, 2014]

CHIMBUTANE, F. (2011). Rethinking bilingual education in postcolonial contexts. Bristol, Bufallo, Toronto: Multilingual Matters.

Cliatt, M. J. P., \& Shaw, J. M. (1988). The Storytime Exchange: Ways to Enhance It. Childhood Education, 64(5), 293-298.

COHEN, D. K., \& BALL, D. L. (1990). Policy and practice: An overview. Educational Evaluation and Policy Analysis, 12(3), 233-239.

Craig, S., Hull, K., Haggart, A. G., \& Crowder, E. (2001). Storytelling: Addressing the Literacy Needs of Diverse Learners. TEACHING Exceptional Children, 33(5), 46-51. Retrieved from http://ici-bostonready-pd-20092010.wikispaces.umb.edu/file/view/Storytelling Addressing the Literacy Needs of Diverse Learners.pdf [Accessed: March 15, 2017)

CUMMINS, J. (1991). Interdependence of first- and second-language proficiency in bilingual children. In E. Bialystock (Ed.), Language processing in bilingual children (pp. 70-89). Cambridge University: Cambridge University Press, United Kingdom.

DUTCHER, N. (2004). Expanding educational opportunity in linguistically diverse societies (2nd ed.). Washington DC: Centre for Applied Linguistics.

EKIBIINA KY'OLULIMI OLUGANDA. (1960). Engero Amakumi Abiri mu ebbiri. Great Britain: Longmans.

GOVERNMENT OF UGANDA. (1992). Government white paper on the implementation of the recommendation of the report of Education Review Commission. Kampala: Uganda Government.

HEUGH, K. (2011). Theory and practice - language education models in Africa: research, design, decision-making and outcomes. In A. Ouane \& C. Glanz (Eds.), Optimising learning, education and publishing in Africa: The language factor. A review and analysis of theory and practice in mother-tongue and blingual education in sub-Saharan Africa (pp. 103-156). Hamburg, Germany: UNESCO Institute for Lifelong Learning (UIL) and Association for the Development of Education in Africa (ADEA) / African Development Bank.

HEUGH, K. (2013). Navigating contested space, time, and position: Ethnographic research in bilingual and trilingual education in Ethiopia. In J. A. Shoba \& F. Chimbutane (Eds.), Bilingual education and language policy in the Global South (pp. 104-123). New York \& London: Routledge.

HEUGH, K, BENSON, C., BOGALE, B., \& YOHANNES, M. A. G. (2007). Final report study on medium of instruction in primary schools in Ethiopia.

HORNBERGER, N. (2002). Multilingual language policies and the continua of biliteracy: An ecological approach. Language Policy, 1(1), 27-51. Available from http://dx.doi.org/10.1023/A:1014548611951 [Accessed February 12 2012] 
Hornberger, N. H., \& Skilton-Sylvester, E. (2000). Revisiting the continua of biliteracy: International and critical perspectives. Language and Education, 14(2), 96-112. Available from https://doi.org/10.1080/09500780008666781 [Accessed March 30, 2012]

Hornberger, N. H. ., \& Chick, J. K. (2001). Co-constructing school safetime: Safetalk practices in Peruvian and South African classrooms. In M. Heller \& M. Martin-Jones (Eds.), Voices of Authority: Education and Linguistic Difference (pp. 33-55). Stanford: Ablex.

Kyeyune, R. (2003). Challenges of using English as a medium of instruction in multilingual contexts: A view from Ugandan classrooms. Language, Culture and Curriculum, 16(2), $173-184$.

MAKONI, S. (2011). A critical analysis of the historical and contemporary status of minority languages in Zimbabwe. Current Issues in Language Planning, 12(4), 437-455.

MANYAK, PC. (2006). Fostering biliteracy in a monolingual milieu: Reflections on two counter-hegemonic English immersion classes. Journal of Early Childhood Literacy, 6, 241-266. Available from https://doi.org/DOI: 10.1177/1468798406069798 [Accessed March 30, 2012]

MARTIN-JONES, M. (2011). Languages, texts, and literacy practices: An ethnographic lens on bilingual vocational education in Wales. In T. L. MacCarty (Ed.), Ethnography and Language policy (pp. 232-253). New York and London: Routledge.

McLAUGHLIN, B. (1992). Myths and misconceptions about second language learning: What every teacher needs to unlearn.

MILLER, S., \& PENNYCUFF, L. (2008). The power of story: Using storytelling to improve literacy learning. Journal of Cross-Disciplinary Perspectives in Education, 1(1), 36-43.

MUSHENGYEZI, A. (2003). Rethinking indigenous media: rituals, 'talking' drums and orality as forms of public communication in Uganda. Journal of African Cultural Studies, 16(1), 107-117.

MUSHI, P. A. K. (2009). History of Education in Tanzania. Dar-esSalaam: Dar-esSalaam University Press.

NCDC. (2006a). Teachers' Resource Book (Luganda). Kampala: National Curriculum Development Centre.

NCDC. (2006b). The national primary school curriculum for Uganda, primary 1. Kampala: The National Curriculum Development Centre (NCDC).

NCDC. (2007a). The national primary school curriculum for Uganda: Teachers' guide, primary 1. Kampala: National Curriculum Development Centre (NCDC).

NCDC. (2007b). The National primary school curriculum for Uganda: Teachers' guide P2, terms I, II \& III. Kampala: National Curriculum Development Centre (NCDC).

NCDC. (2008). National primary school curriculum for Uganda: Teacher's guide P3 terms I, II \& III. Kampala, Uganda: National Curriculum Development Centre (NCDC).

NGWARU, J. M. (2011). Transforming classroom discourse and pedagogy in rural Zimbabwe classrooms: the place of local culture and mother tongue use. Language, Culture and Curriculum, 23(3), 221-240. Available from https://doi.org/10.1080/07908318.2011.609624 [Accessed March 15, 2017]

NSIBAMBI, R. (2000). A language policy for national integration. Facilitators and inhibitors. In K. Parry (Ed.), Language and Literacy in Uganda. Kampala: Fountain Publishers Ltd.

P'BITEK., O. (1986). Song of Lawino and Song of Ocol. London: Heinemann.

PALINCSAR, A. S. (1998). Social constructivist perspectives on teaching and learning. Annual Review of Psychology, 49, 345-375.

PARRY, K. (2000). Language and Literacy in Uganda towards a sustainable reading culture. Kampala: Fountain Publishers Ltd. 
PECK, J. (1989). Using storytelling to promote language and literacy development. The Reading Teacher, 43(2), 138-141.

Pedersen, E. M. (1995). Storytelling and the Art of Teaching. FORUM, 33(1). Retrieved from http://dosfan.lib.uic.edu/usia/E-USIA/forum/vols/vol33/no1/P2.htm

[Retrieved: December 31, 2013]

Prosper, A., \& Nomlomo, V. (2016). Literacy for all? Using multilingual reading stories for literacy development in a grade one classroom in the Western Cape. Per Linguam: A Journal of Language Learning, 32(3), 79-94. Available from https://doi.org/http://dx.doi.org/10.5785/32-3-622 [Accessed: March 15, 2017]

SANYU, F. (2000). Difficulties in implementing the policy of Teaching in the Mother Tongue. In Language and literacy in Uganda (pp. 43-45). Kampala: Fountain Publishers Ltd.

SEGGANYI, E. A. K., Kizito, E. K., \& Mukalazi, Y. K. S. (1958). Ssebato Bafuma. Nairobi, Kenya: East African Literature Bureau.

SHOHAMY, E. (2006). Language policy: Hidden agendas and new approaches. New York: Routledge.

SSEKAMWA, J. C. (2000). History and development of education in Uganda (2nd ed.). Kampala, Uganda: Fountain Publishers Ltd.

SSENTANDA, M. E. (2013). Exploring connections: Reflections on mother-tongue education in postcolonial Uganda. Stellenbosch Papers in Linguistics Plus, 42, 281-296.

SSENTANDA, M. E. (2014). The Challenges of Teaching Reading in Uganda: Curriculum guidelines and language policy viewed from the classroom. Apples - Journal of Applied Language Studies, 8(2), 1-22.

SSENTANDA, M. E., HUDDLESTONE, K., \& SOUTHWOOD, F. (2016). The politics of mother tongue education: the case of Uganda. Per Linguam: A Journal of Language Learning, 32(3), 60-78. Available from https://doi.org/10.5785/32-3-689 Accessed August 20, 2016]

SSENTANDA, M. E., SOUTHWOOD, F., \& HUDDLESTONE, K. (2019). Curricula expectations versus teachers' opinions and practices in teaching English in rural primary schools in Uganda. Language Matters, 50(2), 141-163.

STRANGER-JOHANNESSEN, E., \& NORTON, B. (2017). The African Storybook and Language Teacher Identity in Digital Times. The Mordern Language Journal, 101(Supplement), 45-60.

TEMBE, J., \& REED, Y. (2016). Languaging in and about Lunyole: African Storybook materials as a catalyst for re-imagining literacy teaching and learning in two Ugandan primary schools. Reading \& Writing, 7(2), 2308-1422. Available from https://doi.org/http:// dx.doi.org/10.4102/rw. v7i2.115 [Accessed March 15, 2017]

TIBERONDWA, A. K. (1998). Missionary teachers as agents of colonialism: a study of their activities in Uganda, 1877-1925. Kampala: Fountain Publishers Ltd.

VAMBE, M. T. (2001). Orality and cultural identities in Zimbabwe / monograph. Gweru, Zimbabwe: Mambo Press.

Wa THIONG, N. (1986). Decolonising the mind: The politics of language in African literature. Kenya: East African Educational Publishers. 


\section{BIOGRAPHICAL NOTES}

Medadi E Ssentanda (PhD) is a Lecturer at Makerere University, Department of African Languages (Uganda) and a Research Associate at Stellenbosch University (South Africa). His research interests are language policy in the school context, mother tongue education, classroom interactions and linguistic landscape.

Samuel Andema (PhD) is an Assistant Professor of language and literacy education at Aga Khan University (AKU), Institute for Educational Development, East Africa (IED, EA), based in Dar es Salaam, Tanzania. His research interests focus on digital literacy, local cultural and linguistic resources and classroom practices. 